\title{
Boosting Synergistic Effects of Short Antimicrobial Peptides With Conventional Antibiotics Against Resistant Bacteria
}

\author{
Chih-Lung Wu ${ }^{1 \dagger}$, Kuang-Li Peng ${ }^{1 \dagger}$, Bak-Sau Yip ${ }^{1,2+}$, Ya-Han Chih ${ }^{1}$ and Jya-Wei Cheng ${ }^{1 *}$ \\ ${ }^{1}$ Department of Medical Science, Institute of Biotechnology, National Tsing Hua University, Hsinchu, Taiwan, ${ }^{2}$ Department \\ of Neurology, National Taiwan University Hospital Hsinchu Branch, Hsinchu, Taiwan
}

OPEN ACCESS

Edited by:

Octavio Luiz Franco,

Catholic University of Brasilia (UCB),

Brazil

Reviewed by:

Hashem Etayash,

University of British Columbia,

Canada

Paula Jorge

University of Minho, Portugal

*Correspondence:

Jya-Wei Cheng

jwcheng@life.nthu.edu.tw

${ }^{\dagger}$ These authors have contributed equally to this work

Specialty section:

This article was submitted to Antimicrobials, Resistance

and Chemotherapy,

a section of the journa

Frontiers in Microbiology

Received: 26 July 2021 Accepted: 27 September 2021

Published: 18 October 2021

Citation:

Wu C-L, Peng K-L, Yip B-S, Chih Y-H and Cheng J-W (2021) Boosting Synergistic Effects of Short

Antimicrobial Peptides With Conventional Antibiotics Against

Resistant Bacteria.

Front. Microbiol. 12:747760. doi: 10.3389/fmicb.2021.747760
The global spread of antibiotic-resistant infections has meant that there is an urgent need to develop new antimicrobial alternatives. In this study, we developed a strategy to boost and/or synergize the activity of conventional antibiotics by combination with antimicrobial peptides tagged with the bulky non-natural amino acid $\beta$-naphthylalanine (Nal) to their $\mathrm{N}$ - or $\mathrm{C}$-terminus. A checkerboard method was used to evaluate synergistic effects of the parent peptide and the Nal-tagged peptides. Moreover, boron-dipyrromethene labeled vancomycin was used to characterize the synergistic mechanism of action between the peptides and vancomycin on the bacterial strains. These Nal-tagged antimicrobial peptides also reduced the antibiotic-induced release of lipopolysaccharide from Gram-negative bacteria by more than 99.95\%. Our results demonstrate that Nal-tagged peptides could help in developing antimicrobial peptides that not only have enhanced antibacterial activities but also increase the synergistic effects with conventional antibiotics against antibiotic-resistant bacteria.

Keywords: antimicrobial peptides (AMP), antibiotic resistance, synergism, bulky non-natural amino acid, end-tagging

\section{INTRODUCTION}

The emergence of multidrug-resistant pathogens emphasizes the need for novel and alternative therapeutics to fight against infections (Marston et al., 2016). Some AMPs can work synergistically with conventional antibiotics to overcome the resistant problems and reduce the amount of antibiotics (Cassone and Otvos, 2010; Sierra et al., 2017; Martinez et al., 2019; Zharkova et al., 2019; Li et al., 2020). However, rules governing the design of AMPs with synergistic effects are still not clear (Lazar et al., 2018).

Tryptophan, owing to its membrane disruptive and lipid interface anchoring activities, has been found to play important roles in the design and development of Trp-rich AMPs (Mojsoska and Jenssen, 2015; Godballe et al., 2016; Arias et al., 2018). Previously, a Trp-rich peptide PEM2-W5K/A9W (Ac-KKWRKWLKWLAKK- $\mathrm{NH}_{2}$ ) was developed based on the C-terminal region of Bothrops asper myotoxin II (Yu et al., 2010). PEM-2-W5K/A9W was found to possess strong 
activities against both bacteria and fungi even under high salt conditions (Yu et al., 2010). However, peptide S1 (Ac-KKWRKWLAKK-NH $\mathrm{N}_{2}$ ), a shortened version of PEM2-W5K/A9W, only had antimicrobial activities in the low salt LYM broth media (Chu et al., 2013). The antimicrobial activities of $\mathrm{S} 1$ were diminished at high salt concentrations.

Several problems such as salt resistance, proteolytic stability, as well as the lipopolysaccharide (LPS, endotoxin) outer membrane of bacteria may hinder the development of AMPs (Chu et al., 2013; Chih et al., 2015, 2019). Recent studies have indicated that the salt resistance, serum proteolytic stability, and LPS neutralizing activities can be increased by adding bulky nonnatural amino acids to the termini of short AMPs such as peptide S1 (Chu et al., 2013; Chih et al., 2015). Nuclear magnetic resonance structures have shown that the two terminal $\beta$-naphthylalanine residues of $\mathrm{S} 1-\mathrm{Nal}-\mathrm{Nal}$ were inserted into the hydrophobic lipid A motif of LPS micelles and enhanced membrane permeabilization and translocation of this peptide (Yu et al., 2017). Similar results were also observed by adding hydrophobic oligopeptide end tags to the termini of AMPs (Schmidtchen et al., 2009, 2011; Song et al., 2019).

Evidence has highlighted the synergistic effects of using AMPs in combination with conventional antibiotics against multidrug-resistant bacterial strains. For example, polymyxin B and its derivatives were found to function as "permeabilizers" or "potentiators" to sensitize bacteria to other antibiotics or potentiate the action of other antibiotics by interacting with anionic lipopolysaccharide (LPS) outer leaflet of Gramnegative bacteria (Vaara, 2019). It was also shown that multidrug-resistant bacteria frequently show collateral sensitivity to AMPs (Lazar et al., 2018). This finding can be used to develop peptide-antibiotic combinations that can fight against resistant bacteria (Lazar et al., 2018). Zharkova et al. (2019) also found that synergism mainly occurs between highly membrane-active AMPs and antibiotics with intracellular targets. Cytotoxicity of these combinations toward normal eukaryotic cells were rarely synergistic (Zharkova et al., 2019). In addition, a bulky non-natural amino acid substituted version of the antimicrobial peptide Bip-P-113 was found to act as a potentiator to sensitize vancomycin against Gram-negative bacteria such as Escherichia coli and to boost synergistic effects with vancomycin against drug-resistant Gram-positive bacteria (Wu et al., 2020).

The aim of this study was to test if the bulky non-natural amino acid end tagging strategy of short AMPs can be used in combination with various antibiotics to fight against antibioticresistant bacterial strains. These results could provide important insights into the synergistic mechanism between AMPs and traditional antibiotics.

\section{MATERIALS AND METHODS}

\section{Materials}

S1, S1-Nal, and S1-Nal-Nal (Table 1) were purchased from Kelowna International Scientific Inc. (Taipei, Taiwan). The identity of the peptides was confirmed by electrospray
TABLE 1 | Sequences of S1, S1-Nal, and S1-Nal-Nal.

\begin{tabular}{lcc}
\hline Name & Sequence $^{\text {a }}$ & Molecular weight (Da) \\
\hline S1 & Ac-KKWRKWLAKK-NH2 & $1,412.79$ \\
S1-Nal & Ac-KKWRKWLAKK-Nal-NH2 & $1,609.98$ \\
S1-Nal-Nal & Ac-KKWRKWLAKK-Nal-Nal-NH2 & $1,806.99$
\end{tabular}

a Nal, $\beta$-naphthylalanine.

mass spectroscopy and the purity (>95\%) was assessed by high-performance liquid chromatography. Both identity and purity data were provided by Kelowna International Scientific Inc. (Taipei, Taiwan). Tetracycline, ciprofloxacin and vancomycin were purchased from Bio Basic Inc. (Toronto, ON, Canada). BODIPY-labeled Vancomycin was obtained from Thermo Fisher Scientific (Waltham, MA, United States). Mueller-Hinton broth (MHB), Tryptic soy broth (TSB) were purchased from Becton, Dickinson and Company (Franklin Lakes, NJ, United States). Calcein-AM dye was obtained from Sigma-Aldrich (St. Louis, MO, United States).

\section{Bacterial Strains and Culture Conditions}

Enterococcus faecium (BCRC 15B0132, VRE), Acinetobacter baumannii strains including 14B0091, 14B0097, and 14B0100, and E. coli strains including BCRC 13 B0198 and BCRC 13B0207 were purchased from Bioresources Collection \& Research Center ${ }^{1}$ (BCRC, FIRDI, Hsinchu, Taiwan). Escherichia coli and A. baumannii strains were incubated in $\mathrm{MHB}$, and E. faecium BCRC 15B0132 were incubated in TSB overnight at $37^{\circ} \mathrm{C}$ with $150 \mathrm{rpm}$ shaking overnight. The turbidity of bacteria was measured by the absorbance of optical density at $600 \mathrm{~nm}\left(\mathrm{OD}_{600}=1\right.$, equal to approximately $\left.10^{8} \mathrm{CFU} / \mathrm{mL}\right)$ with UV/Visible spectrophotometer (Biochrom, Cambridge, United Kingdom).

\section{Antimicrobial Activity Assay}

The minimal inhibitory concentrations (MICs) of peptides and antibiotics were determined by using microbroth dilution technique, as described by the guidelines of the Clinical and Laboratory Standards Institute (CLSI) (2015). The assay was conducted manually using the single pipette following the CLSI with some modifications. Briefly, E. coli and A. baumannii strains were incubated in $\mathrm{MHB}$, and $E$. faecium BCRC $15 \mathrm{~B} 0132$ were incubated in TSB overnight at $37^{\circ} \mathrm{C}$. The cell cultures were regrown to mid-log phase and then diluted to a final concentration of $5 \times 10^{5} \mathrm{CFU} / \mathrm{mL}$. $99 \mu \mathrm{l}$ of each diluted microbes were transferred into each well of a 96-well plate, into which $1 \mu$ l of peptides or antibiotics has previously been added and the final concentration of the peptides and antibiotics would be $64-0.13 \mu \mathrm{g} / \mathrm{mL}$. After incubation for about $16 \mathrm{~h}$ at $37^{\circ} \mathrm{C}$, the $\mathrm{MIC}$ value of peptides or antibiotics was determined by inspecting the visible growth. The MIC value was defined as the lowest concentration of an antimicrobial that will inhibit the visible growth of a microorganism. All experiments were repeated three times independently.

\footnotetext{
${ }^{1}$ https://catalog.bcrc.firdi.org.tw/
} 


\section{Checkerboard Assay}

The synergistic effects of peptides in combination with antibiotics was assessed by using the microbroth dilution checkerboard assay (Mataraci and Dosler, 2012; Mohamed et al., 2016). Each well containing the mixture of $1 \mu \mathrm{l}$ peptide $(1 / 4 \times$ MIC at final concentration) and $1 \mu \mathrm{l}$ antibiotic $(64-0.13 \mu \mathrm{g} / \mathrm{mL}$ at final concentration), and loaded $98 \mu \mathrm{l}$ bacteria at the final concentration of $5 \times 10^{5} \mathrm{CFU} / \mathrm{mL}$ into each well of a 96-well plate. After incubation for about $16 \mathrm{~h}$ at $37^{\circ} \mathrm{C}$, the MIC value of peptide/antibiotic combination was determined by inspecting the visible growth. MIC values obtained were used to evaluate the effects of combination between peptides and antibiotics by calculating the Fractional Inhibitory Concentration Index (FICI) according to the following formula:

$$
\mathrm{FICI}=\frac{\mathrm{MIC}_{A} \text { in combination }}{\mathrm{MIC}_{A} \text { alone }}+\frac{\mathrm{MIC}_{B} \text { in combination }}{\mathrm{MIC}_{B} \text { alone }}
$$

The calculated FICI was interpreted as synergistic (FICI $\leq 0.5)$, no interaction $(0.5<\mathrm{FICI} \leq 4)$, or antagonistic $($ FICI $>4)($ Odds, 2003). The experiments were repeated three times independently.

\section{Confocal Laser Scanning Microscopy}

The fluorescence experiments were performed with slight modification as described previously (Joshi et al., 2010). Briefly, the bacteria were diluted to $10^{7} \mathrm{CFU} / \mathrm{mL}$ and incubated with S1, S1-Nal, and S1-Nal-Nal peptides at $0.5 \times$ MIC for 30 mins. Then, $2 \mu \mathrm{g} / \mathrm{mL}$ BODIPY-labeled vancomycin were treated for 30 mins. Bacteria treated with BODIPY-labeled vancomycin only served as a control. After treatment, the cell pellet was obtained by centrifugation and washed with PBS to remove free BODIPY-labeled vancomycin. The pellet was resuspended and loaded on the glass slides (Polysine ${ }^{\mathrm{TM}}$, Thermo Fisher Scientific, Waltham, MA, United States) and visualized under confocal laser scanning microscope (LSM 510 META, Carl Zeiss, Jena, Thüringen, Germany) equipped with $64 \times$ oil objective lens (Carl Zeiss, Jena,
Thüringen, Germany). All experiments were repeated three times independently.

\section{Calcein Leakage Assay}

Calcein acetoxymethyl ester (calcein-AM) is a non-fluorescent dye and enters into the bacteria through diffusing across the cell membrane, and hydrolyzed to fluorescent calcein $\left(\mathrm{C}_{30} \mathrm{H}_{26} \mathrm{~N}_{2} \mathrm{O}_{13}\right)$ by cytoplasmic esterases (Xiong et al., 2005). Briefly, the microbes were grown to mid-log phase and the pellet was obtained by centrifugation, washed with PBS, resuspended to $\mathrm{OD}_{600}$ of 1.0 with $\mathrm{PBS}$ containing $10 \%$ ( $\mathrm{vol} / \mathrm{vol}$ ) broth. The microbes were incubated with $3 \mu \mathrm{M}$ calcein-AM for $1 \mathrm{~h}$ at $37^{\circ} \mathrm{C}$ to form calcein-AM loaded cells. The calceinAM loaded cells were collected by centrifugation $(3,000 \times g$, 10 mins), and resuspended to $10^{7} \mathrm{CFU} / \mathrm{ml}$ by PBS. Cobalt was added into cells and was used to quench the fluorescence of calcein released into the extracellular environment. The cells were treated with $0.5 \times$ MIC of peptides in the sterile blackwall 96-well plate and measured the fluorescence intensity for $60 \mathrm{mins}$ at an excitation wavelength of $485 \mathrm{~nm}$ and an emission wavelength of $510 \mathrm{~nm}$ on a fluorescence plate reader (VICTOR3, PerkinElmer, United States) (Essodaigui et al., 1998). Bacteria treated with $\mathrm{H}_{2} \mathrm{O}$ served as negative controls. The intensity of membrane permeabilization (\%) was calculated as the absolute percent calcein leakage by peptides with respect to non-treated calcein-AM loaded cells (Koo et al., 2001). All experiments were repeated three times independently.

\section{Anti-endotoxin Studies}

Escherichia coli BCRC 13B0198 were cultured at the mid-log phase and diluted to $10^{4} \mathrm{CFU} / \mathrm{ml}$, and then treated with peptide alone at $1 \times$ MIC or combination with vancomycin (both at $0.5 \times \mathrm{MIC})$ at $37^{\circ} \mathrm{C}$ for $6 \mathrm{~h}$. The cells were filtered by using a pyrogen-free $0.2 \mu \mathrm{m}$ pore filter (Acrodisc, Pall Corporation, United States) and the endotoxin level was determined by limulus amebocyte lysate (LAL) PYROCHROME ${ }^{\circledR}$ test (Associates of Cape Cod, United States). The kinetic turbidity was analyzed by

TABLE 2 | The minimal inhibitory concentrations (MICs) of S1, S1-Nal, S1-Nal-Nal, vancomycin, ciprofloxacin, and tetracycline.

\begin{tabular}{|c|c|c|c|c|c|c|}
\hline \multirow[t]{2}{*}{ Bacterial strains } & \multicolumn{6}{|c|}{$\mathrm{MIC}^{\mathrm{a}}(\mu \mathrm{g} / \mathrm{ml})$} \\
\hline & S1 & S1-Nal & S1-Nal-Nal & Vancomycin & Ciprofloxacin & Tetracycline \\
\hline $\begin{array}{l}\text { Acinetobacter baumannii } \\
\text { BCRC 14B0091 }\end{array}$ & $>64$ & 8 & 2 & $>64$ & 32 & $>64$ \\
\hline $\begin{array}{l}\text { Acinetobacter baumannii } \\
\text { BCRC } 14 \mathrm{~B} 0100\end{array}$ & $>64$ & 8 & 4 & $>64$ & 64 & $>64$ \\
\hline $\begin{array}{l}\text { Escherichia coli } \\
\text { BCRC 13B0198 }\end{array}$ & 64 & 32 & 16 & $>64$ & 32 & $>64$ \\
\hline $\begin{array}{l}\text { Escherichia coli } \\
\text { BCRC 13B0207 }\end{array}$ & $>64$ & 32 & 16 & $>64$ & 0.25 & $>64$ \\
\hline
\end{tabular}

aMIC, minimum inhibitory concentration. 

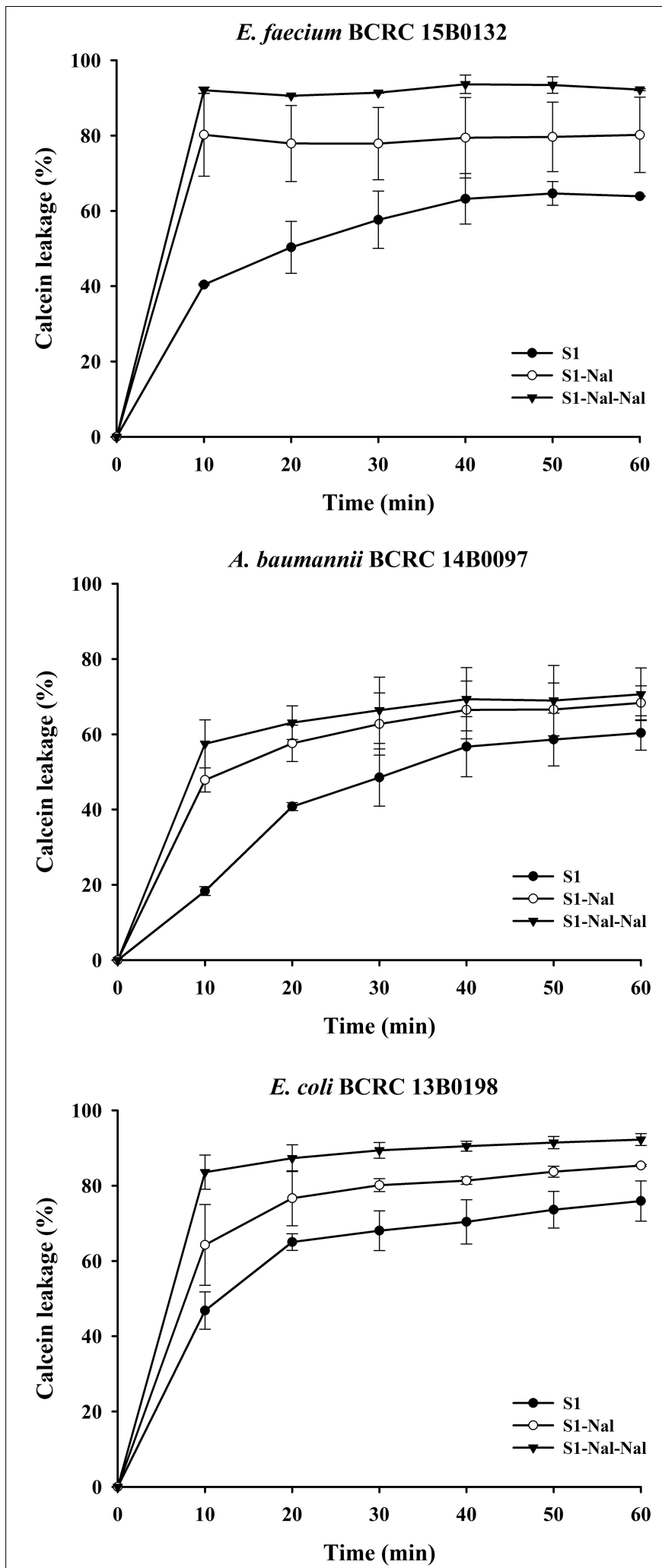

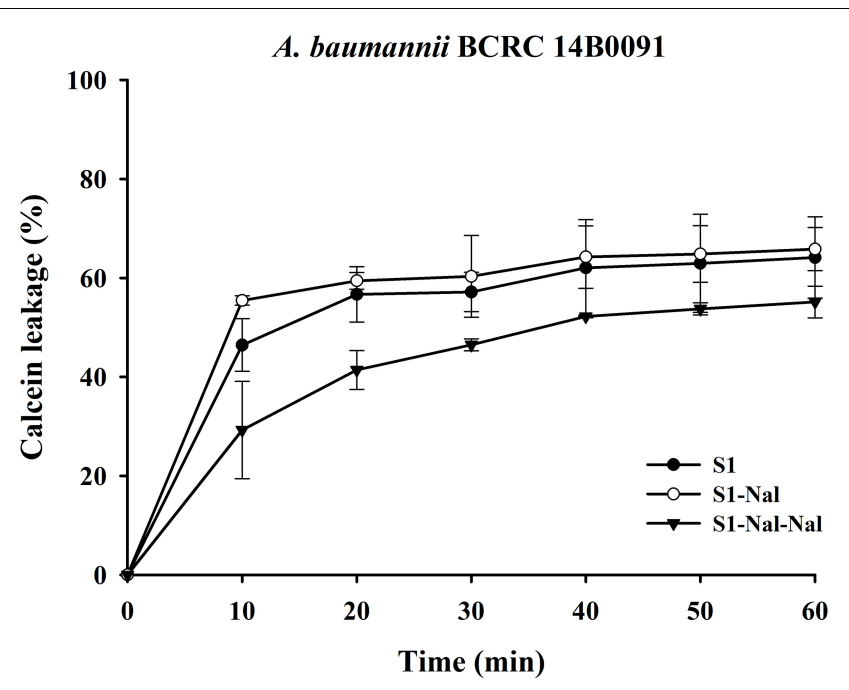

A. baumannii BCRC 14B0100

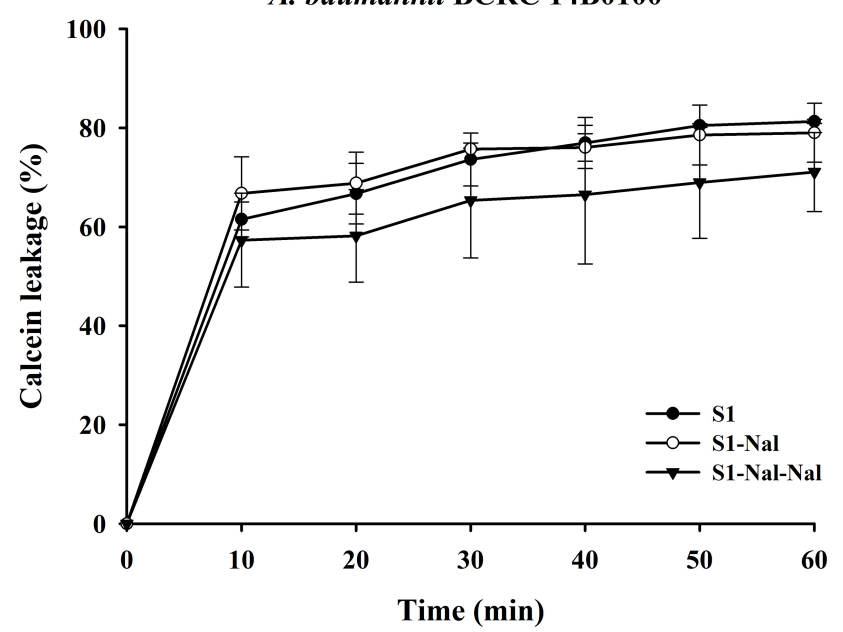

E. coli BCRC 13B0207

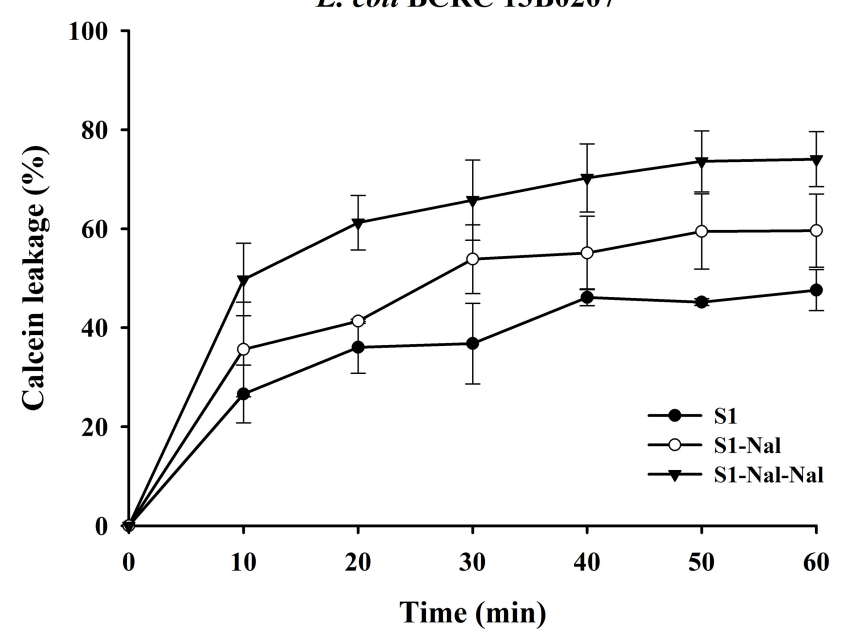

FIGURE 1 | The membrane permeabilization of Enterococcus faecium BCRC 15B0132, Acinetobacter baumannii BCRC 14B0091, A. baumannii BCRC 14B0097, A. baumannii BCRC 14B0100, Escherichia coli BCRC 13B0198, and E. coli BCRC 13B0207, by S1, S1-Nal, and S1-Nal-Nal for 60 min exposure. Calcein-AM loaded cells $\left(10^{7} \mathrm{CFU} / \mathrm{ml}\right)$ were resuspended by PBS, and the aliquots of $100 \mu \mathrm{l}$ were added into a sterile black-wall 96 -well plate, then treated with $0.5 \times \mathrm{MIC}$ of peptides in each well and measured the calcein leakage immediately. Each time point for the peptides was repeated three times independently. 
using a microplate reader (SpectraMax ABS, Molecular Devices, San Jose, CA, United States). The experiments were repeated three times independently.

\section{Statistical Analysis}

The statistical results are performed as the mean \pm SEM and were analyzed using one-way ANOVA analysis of variance. Statistical analysis was performed using GraphPad Prism version 8.0 (San Diego, CA, United States), where $p<0.05$ was considered to indicate a statistically significant difference.

\section{RESULTS}

\section{Antimicrobial Activity}

The antibacterial activities of S1, S1-Nal, S1-Nal-Nal, vancomycin, ciprofloxacin, and tetracycline against Grampositive bacterium including vancomycin-resistant E. faecium BCRC 15B0132 (VRE) and Gram-negative bacteria including A. baumannii BCRC 14B0091, A. baumannii BCRC 14B0097, A. baumannii BCRC 14B0100, E. coli BCRC 13B0198, and E. coli BCRC $13 \mathrm{~B} 0207$ were assessed by MIC assay. As shown in Table 2, antibiotics, including vancomycin, ciprofloxacin, and tetracycline had limited or no activities against all bacterial strains except for E. coli BCRC 13B0207, which is sensitive to ciprofloxacin. S1 peptide also had limited or no antibacterial activities (>64 $\mu \mathrm{g} / \mathrm{ml})$. On the other hand, peptides S1-Nal and S1-Nal-Nal with the addition of bulky non-natural amino acid $\beta$-naphthylalanine at the C-termini demonstrated enhanced activities against all bacterial strains. S1-Nal had the MICs of $64 \mu \mathrm{g} / \mathrm{ml}$ against E. faecium, $8 \mu \mathrm{g} / \mathrm{ml}$ against $A$. baumannii, and $32 \mu \mathrm{g} / \mathrm{ml}$ against E. coli. S1-Nal-Nal had the MICs of $32 \mu \mathrm{g} / \mathrm{ml}$ against E. faecium, $2 \mu \mathrm{g} / \mathrm{ml}$ against $A$. baumannii BCRC 14B0091, $4 \mu \mathrm{g} / \mathrm{ml}$ against A. baumannii BCRC 14B0100, $8 \mu \mathrm{g} / \mathrm{ml}$ against A. baumannii BCRC 14B0097, and $16 \mu \mathrm{g} / \mathrm{ml}$ against $E$. coli. These results indicated that the addition of only one or two bulky non-natural amino acid end tags could boost the antimicrobial activity.

\section{Bacterial Membrane Permeabilization}

Permeabilities of S1, S1-Nal, and S1-Nal-Nal were measured by the peptide-induced leakage of the fluorescent dye calcein from bacterial cells (Figure 1). To determine the mechanism of antibacterial action of the AMPs, we evaluated the ability of peptides to permeabilize intact E. faecium, A. baumannii, and E. coli membranes by measuring the peptide-induced leakage of the fluorescent dye calcein from bacterial cells (Figure 1). In general, the permeabilization ability is in the order of S1-Nal-Nal $>$ S1-Nal $>$ S1. Addition of $\beta$-naphthylalanine to the termini of S1-Nal and S1-Nal-Nal can increase permeability from 60 to $90 \%$ for E. faecium, from 50 to $60 \%$ for A. baumannii BCRC 14B0097, from 65 to $90 \%$ for E. coli BCRC13B0198, and from 40 to $70 \%$ for E. coli BCRC13B0207. However, for bacterial strains A. baumannii BCRC 14B0091 and A. baumannii BCRC 14B0100, the order of the permeabilization ability is $\mathrm{S} 1-\mathrm{Nal}=\mathrm{S} 1>\mathrm{S} 1$ Nal-Nal. Nevertheless, All peptides showed substantial release of calcein from these six bacterial cells.

\section{Synergistic Effect With Vancomycin, Ciprofloxacin, and Tetracycline in the Presence of a Sub-Inhibitory Concentration ( $1 / 4 \times$ Minimal Inhibitory Concentrations) of Peptides}

Based on the strong antimicrobial activity and bacterial membrane permeability, it is suggested that these peptides could be used to potentiate conventional antibiotics such as vancomycin, ciprofloxacin, and tetracycline against antibioticresistant Gram-positive and Gram-negative bacterial strains. Synergetic activities of S1, S1-Nal, and S1-Nal-Nal combined with vancomycin, ciprofloxacin, and tetracycline were then determined by the checkerboard assay (Table 3). For E. faecium BCRC 15B0132 and A. baumannii BCRC 14B0097, S1-Nal-Nal showed substantial synergy while combined with vancomycin, ciprofloxacin, and tetracycline. The order of the synergistic effects against $E$. faecium BCRC $15 \mathrm{~B} 0132$ and A. baumannii BCRC $14 \mathrm{~B} 0097$ is S1-Nal-Nal > S1-Nal > S1. For A. baumannii BCRC 14B0091 and A. baumannii BCRC 14B0100, S1-Nal demonstrated better synergistic effects than S1-Nal-Nal and S1. For E. coli BCRC 13B0198, all peptides had strong synergy while combined with ciprofloxacin and vancomycin, but these three peptides had only limited or no synergy while combined with tetracycline. For E. coli BCRC 13B0207, all peptides

TABLE 3 | Synergistic effects of S1, S1-Nal, and S1-Nal-Nal in combination with antibiotics against bacterial strains studied.

\begin{tabular}{|c|c|c|c|c|c|c|c|}
\hline \multirow[t]{3}{*}{ Strains } & \multirow{3}{*}{$\begin{array}{l}\text { Antibiotics } \\
(\mu \mathrm{g} / \mathrm{mL})\end{array}$} & \multicolumn{6}{|c|}{ AMP $(\mu \mathrm{g} / \mathrm{mL})(1 / 4 \times$ MIC $)$} \\
\hline & & \multicolumn{2}{|c|}{ s1 } & \multicolumn{2}{|c|}{ S1-Nal } & \multicolumn{2}{|c|}{ S1-Nal-Nal } \\
\hline & & + & $\mathrm{FICl}^{\mathrm{a}}$ & + & $\mathrm{FICl}$ & + & $\mathrm{FICl}$ \\
\hline \multirow{3}{*}{$\begin{array}{l}\text { Enterococcus } \\
\text { faecium } \\
\text { BCRC 15B0132 }\end{array}$} & Vancomycin & $>64$ & 1.25 & 8 & 0.31 & 2 & 0.27 \\
\hline & Ciprofloxacin & 64 & 0.75 & 16 & 0.38 & 2 & 0.27 \\
\hline & Tetracycline & 16 & 0.5 & 8 & 0.38 & 1 & 0.27 \\
\hline \multirow{3}{*}{$\begin{array}{l}\text { Acinetobacter } \\
\text { baumannii } \\
\text { BCRC 14B0091 }\end{array}$} & Vancomycin & 16 & 0.38 & 2 & 0.27 & $>64$ & 1.25 \\
\hline & Ciprofloxacin & 32 & 0.5 & 32 & 0.5 & 64 & 2.25 \\
\hline & Tetracycline & 64 & 0.75 & 32 & 0.5 & $>64$ & 1.25 \\
\hline \multirow{3}{*}{$\begin{array}{l}\text { Acinetobacter } \\
\text { baumannii } \\
\text { BCRC 14B0097 }\end{array}$} & Vancomycin & 32 & 0.5 & 2 & 0.27 & 2 & 0.27 \\
\hline & Ciprofloxacin & $>64$ & 1.25 & 64 & 0.75 & 2 & 0.27 \\
\hline & Tetracycline & 64 & 0.75 & 64 & 0.75 & 2 & 0.27 \\
\hline \multirow{3}{*}{$\begin{array}{l}\text { Acinetobacter } \\
\text { baumannii } \\
\text { BCRC 14B0100 }\end{array}$} & Vancomycin & 32 & 0.5 & 2 & 0.27 & 4 & 0.28 \\
\hline & Ciprofloxacin & 64 & 0.75 & 32 & 0.5 & 32 & 0.75 \\
\hline & Tetracycline & 64 & 0.75 & 64 & 0.75 & $>64$ & 1.25 \\
\hline \multirow{3}{*}{$\begin{array}{l}\text { Escherichia coli } \\
\text { BCRC } 13 \text { B0198 }\end{array}$} & Vancomycin & 32 & 0.5 & 32 & 0.5 & 32 & 0.5 \\
\hline & Ciprofloxacin & 2 & 0.27 & 2 & 0.27 & 2 & 0.31 \\
\hline & Tetracycline & $>64$ & 1.25 & 64 & 0.75 & 64 & 0.75 \\
\hline \multirow{3}{*}{$\begin{array}{l}\text { Escherichia coli } \\
\text { BCRC } 13 \text { B0207 }\end{array}$} & Vancomycin & 64 & 0.75 & $>64$ & 1.25 & 64 & 0.75 \\
\hline & Ciprofloxacin & 0.02 & 0.31 & 0.06 & 0.5 & 0.13 & 0.75 \\
\hline & Tetracycline & 64 & 0.75 & 64 & 0.75 & 64 & 0.75 \\
\hline
\end{tabular}

${ }^{a} \mathrm{FlCl}$, fractional inhibitory concentration index, $\mathrm{FICl} \leq 0.5$, synergy; $0.5<\mathrm{FICl} \leq 4$, no interaction; $\mathrm{FICl}>4$, antagonism.

+ , the MIC of antibiotic in combination with $1 / 4 \times$ MIC antimicrobial peptides (AMPS). Bold values indicated synergistic effects. 
demonstrated strong synergy while combined with ciprofloxacin, but had only limited activity while combined with vancomycin and tetracycline.

\section{Mechanism of the Synergistic Effects Studied by Boron-Dipyrro-Methene Labeled Vancomycin}

Boron-Dipyrro-Methene (BODIPY)-labeled vancomycin was used to study the mechanism of synergistic effects of S1, S1$\mathrm{Nal}$, and S1-Nal-Nal by measuring the uptake of vancomycin in E. faecium BCRC 15B0132, A. baumannii BCRC 14B0097, and E. coli BCRC 13 B0207 strains (Chu et al., 2020). The results demonstrated that $\mathrm{S} 1-\mathrm{Nal}$ and $\mathrm{S} 1-\mathrm{Nal}-\mathrm{Nal}$ with $\beta$-naphthylalanine end-tagging markedly enhanced the entry of BODIPY-labeled vancomycin into the Gram-positive E. faecium BCRC 15B0132 strain (Figure 2). Similar results were also found for the Gram-negative A. baumannii BCRC 14B0097, and E. coli BCRC 13B0207 strains (Figures 3, 4).

\section{S1-Nal and S1-Nal-Nal Attenuate Vancomycin-Induced Lipopolysaccharide Release}

Antibiotic-treatment can cause the release of lipopolysaccharide (LPS, endotoxin) from Gram-negative bacteria into the bloodstream of the host and has been shown to be associated with the deterioration of the patients (Trautmann et al., 1998; Li et al., 2017). Herein, we used LAL assay to measure the concentration of LPS in supernatants induced by the treatment of vancomycin (Figure 5). Escherichia coli BCRC 13B0198 cells were treated with S1, S1-Nal, and S1-Nal-Nal or the combination of vancomycin and the peptides. The LPS concentration decreased tremendously with the S1-Nal, and S1-Nal-Nal treatment alone or the combination of S1-Nal, S1-Nal-Nal, and vancomycin treatment (Figure 5).

\section{DISCUSSION}

End-tagging peptides with hydrophobic moieties have been developed to increase salt resistance and potency of AMPs. For example, tryptophan and/or phenylalanine stretch (Schmidtchen et al., 2009), as well as fatty acid, vitamin E, or cholesterol were added to the termini of short AMPs (Avrahami and Shai, 2002; Makovitzki et al., 2006; Serrano et al., 2009; Rosenfeld et al., 2010; Arnusch et al., 2012). This strategy was modified by adding only one or two $\beta$-naphthylalanine to the termini of short antimicrobial peptide to boost its salt resistance, serum proteolytic stability and antiendotoxin activities (Chu et al., 2013; Chih et al., 2015). There are several advantages to using $\beta$-naphthylalanine than using tryptophan/phenylalanine or fatty acid as end-tags. For example, a stretch of five tryptophan endtags were needed to provide salt resistance to the antimicrobial peptide KNK10 under $150 \mathrm{mM} \mathrm{NaCl}$ (Pasupuleti et al., 2009). Only one $\beta$-naphthylalanine end-tag was needed to provide substantial salt resistance (Chu et al., 2013). Furthermore, $\beta$-naphthylalanine end-tags can provide superior serum stability

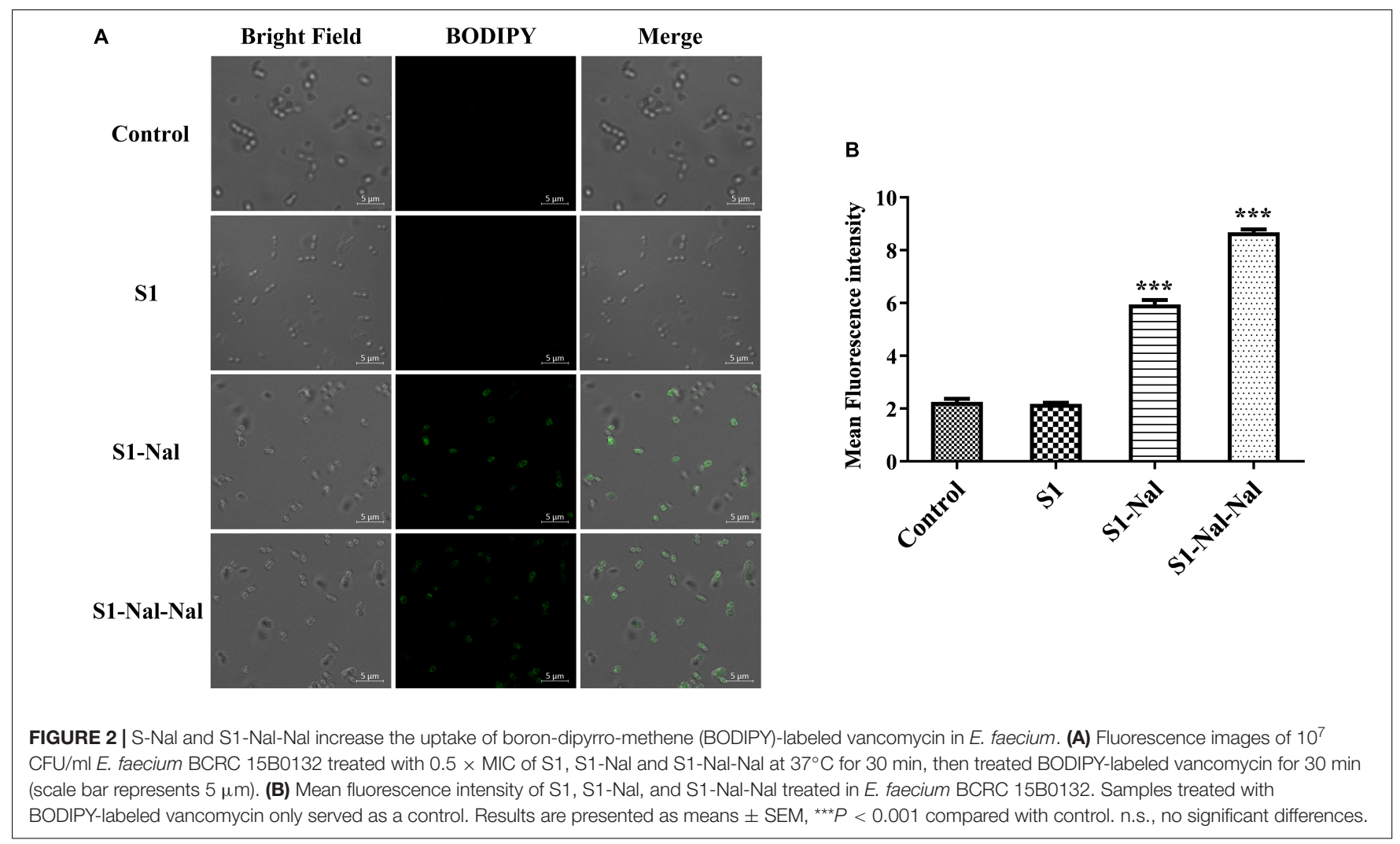



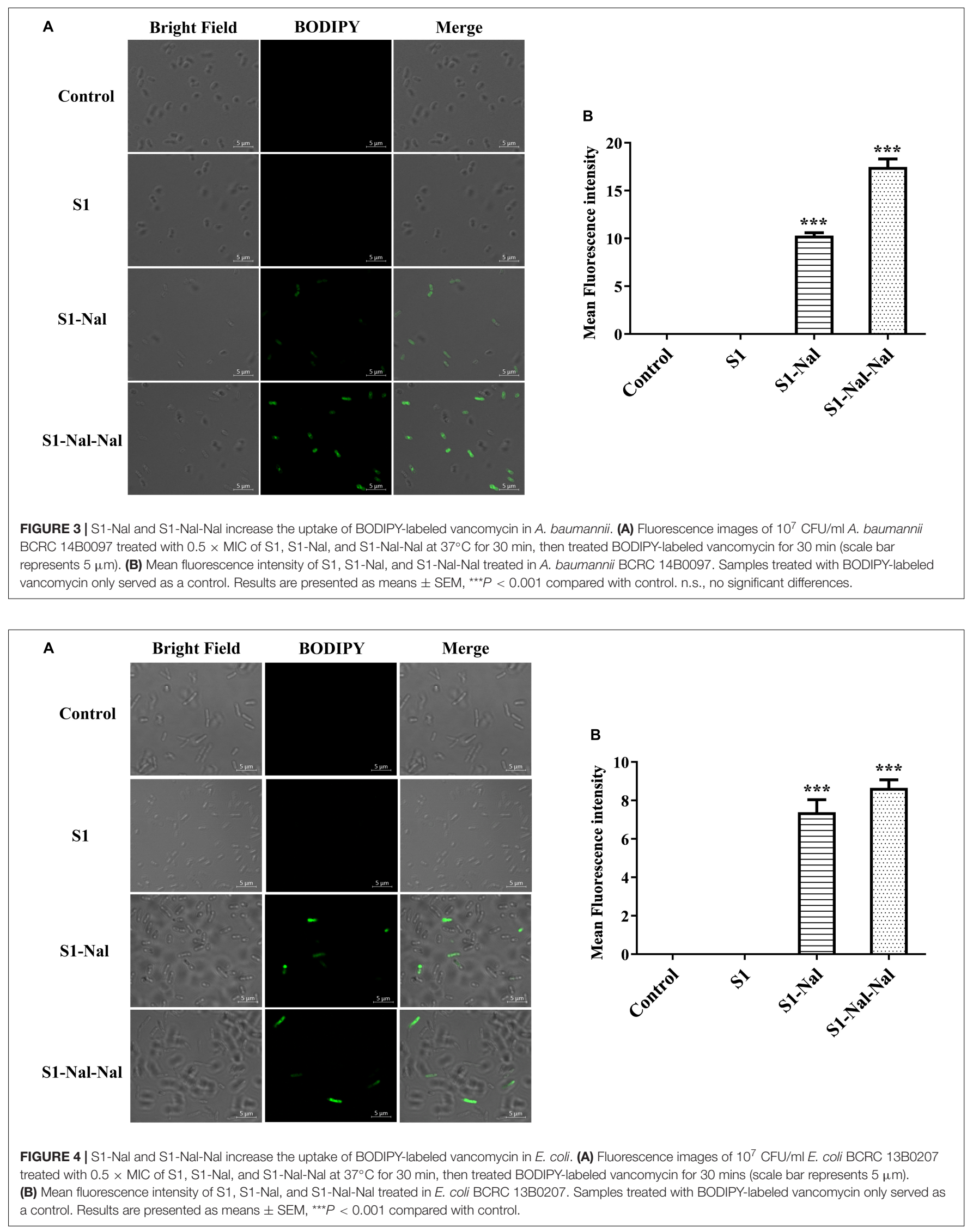


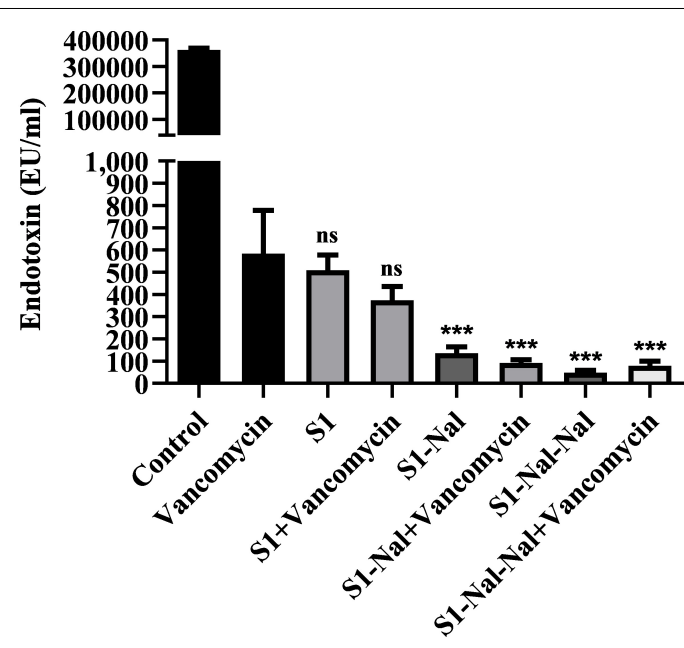

FIGURE 5 | Attenuation of LPS release from E. coli. Escherichia coli BCRC $13 \mathrm{~B} 0198$ were incubated at the mid-log phase $\left(10^{4} \mathrm{CFU} / \mathrm{ml}\right)$ and treated with peptide alone (at $1 \times \mathrm{MIC}$ ) or combination with vancomycin (both at $0.5 \times \mathrm{MIC}$ ) at $37^{\circ} \mathrm{C}$ for $6 \mathrm{~h}$. The samples were filtered through $0.2 \mu \mathrm{m}$ pore filter and the endotoxin level was detected by $L A L$ assay. ${ }^{\star \star \star} P<0.001$ compared with vancomycin only. ns, no significant differences compared with vancomycin only.

due to its non-natural and bulky characteristics (Chu et al., 2013; Chih et al., 2015). This is particularly important for the development of short AMPs to lower the cost of synthesis. In this study, we have extended the $\beta$-naphthylalanine end-tagging strategy to boost the synergistic effects of S1-Nal and S1-Nal$\mathrm{Nal}$ with conventional antibiotics against drug-resistant bacteria. Our results indicated that both S1-Nal and S1-Nal-Nal displayed synergistic effects in combination with conventional antibiotics such as vancomycin, ciprofloxacin, and tetracycline against the Gram-positive E. faecium BCRC15B0132 strain. S1-Nal or S1-Nal-Nal also displayed synergistic effects with vancomycin and ciprofloxacin against the Gram-negative $A$. baumannii BCRC14B0091, A. baumannii BCRC14B0097, A. baumannii BCRC14B0100, E. coli BCRC13B0198, and E. coli BCRC13B0207 strains. However, lack of synergy with tetracycline for all peptides was found against the A. baumannii BCRC14B0100, E. coli BCRC13B0198, and E. coli BCRC13B0207 strains.

Polymyxin $B$ has been used as a potentiator to act synergistically with antibiotics against drug-resistant Gramnegative bacteria (Vaara, 2019). The mechanism of synergism was attributed to the increase of bacterial membrane permeabilization caused by polymyxin B (Vaara, 2019). AMP DP7 shows synergistic effects with the antibiotic, azithromycin, against the antibiotic-resistant strains including $S$. aureus and $P$. aeruginosa isolates (Wu et al., 2017). The synergistic effects may be attributed to the cell wall proteins reduced by azithromycin and cell wall disruption by DP7 peptide (Wu et al., 2017). Antimicrobial peptide CLP-19 displayed synergistic effects with antibiotics such as ampicillin, ceftazidime, and levofloxacin against E. coli ATCC 25922 and S. aureus ATCC 29213 (Li et al., 2017). In addition, the CLP-19 and CLP-19/antibiotic combination could induce the generation of hydroxyl radicals from bacteria through depleted NADH, which were related to the synergistic effects of CLP-19/antibiotic combination (Li et al., 2017). As can be seen from Figure $\mathbf{1}$ in this study, increases of membrane permeabilization of $\beta$-naphthylalanine end-tagging against the six bacterial strains studied were found. The results demonstrated that the increase of membrane permeabilization correlated well with synergistic effect with antibiotics against drug-resistant bacterial strains. Moreover, BODIPY-labeled vancomycin was used to study membrane permeabilization and uptake of vancomycin in E. faecium, A. baumannii, and E. coli strains (Figures 2-4). The results indicated that the antimicrobial peptide-induced fluorescent intensity changes of BODIPYlabeled vancomycin inside bacterial cells were concordant with the membrane permeability of the peptides. One interesting thing to note from bacterial membrane permeabilization studies is that $\beta$-naphthylalanine end-tags caused higher membrane permeabilization of the Gram-positive bacterial strain (from $60 \%$ calcein leakage of S1 to $90 \%$ calcein leakage of S1-Nal$\mathrm{Nal}$ ) than the Gram-negative bacterial strains (Figure 1). S1$\mathrm{Nal}$ and S1-Nal-Nal both have excellent synergistic effects with vancomycin, ciprofloxacin, and tetracycline against the Grampositive E. faecium BCRC 15B0132 strain (Table 3).

Lipopolysaccharide constitutes the major component of the outer leaflet of Gram-negative bacteria. It was shown that S1-Nal

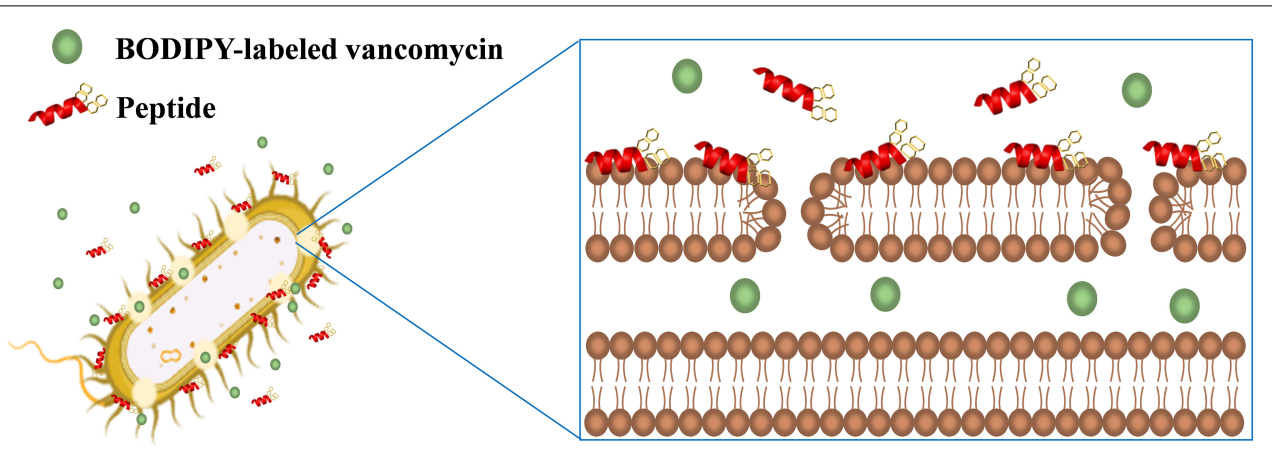

FIGURE 6 | Schematic illustration of the synergistic mechanism for BODIPY-labeled vancomycin and peptides. S1-Nal-Nal (red) disturbs the bacterial outer membrane and enhances the entry of BODIPY-labeled vancomycin (green circle) into bacteria. 
and S1-Nal-Nal possess high antiendotoxin activities (Chih et al., 2015). Furthermore, S1-Nal and S1-Nal-Nal can inhibit LPS-induced nitrite oxide and TNF- $\alpha$ production in murine macrophage cells and suppress TNF- $\alpha$ release in endotoxemia mouse model (Chih et al., 2015). NMR structural studies of S1-Nal-Nal and LPS micelles complex indicated that S1-Nal$\mathrm{Nal}$ rotated its two terminal $\beta$-naphthylalanine residues into the hydrophobic lipid A motif of LPS micelles and blocked the LPSinduced inflammation (Yu et al., 2013). We and others have demonstrated that some AMPs may reduce antibiotic-induced release of LPS from Gram-negative bacteria (Li et al., 2017; Chu et al., 2020). In this study, we have found that S1-Nal and S1-Nal-Nal can reduce antibiotic-induced release of LPS from E. coli (Figure 5).

Vancomycin was shown to act synergistically with AMPs against vancomycin-persistent Gram-positive bacterial cells (Feng et al., 2015). However, vancomycin itself has no antibacterial effect against Gram-negative bacteria due to the LPS outer leaflet preventing large glycopeptide antibiotics such as vancomycin from being transported to intracellular targets. Recently, it was found that vancomycin can eradicate some E. coli cells under cold stress conditions through inhibition of peptidoglycan biosynthesis that is similar to the mechanism of action of vancomycin to Gram-positive bacteria (Stokes et al., 2016). Silver ion was also shown to increase membrane permeability of $E$. coli cells and potentiate vancomycin against E. coli (Morones-Ramirez et al., 2013). In this study, we have also demonstrated that the $\beta$-naphthylalanine end-tagged S1-Nal and S-Nal-Nal can be used with vancomycin to fight against Gram-negative bacterial infections (Figure 6).

In conclusion, we describe a strategy to boost synergistic effects of short AMPs with conventional antibiotics against resistant bacterial strains by adding $\beta$-naphthylalanine (Nal) to one of the peptides' termini. The described Nal-tagged peptides (S1-Nal and S1-Nal-Nal) enhanced the antibacterial activity of

\section{REFERENCES}

Arias, M., Piga, K. B., Hyndman, M. E., and Vogel, H. J. (2018). Improving the activity of Trp-rich antimicrobial peptides by Arg/Lys substitutions and changing the length of cationic residues. Biomolecules 8:19. doi: 10.3390/ biom8020019

Arnusch, C. J., Ulm, H., Josten, M., Shadkchan, Y., Osherov, N., Sahl, H. G., et al. (2012). Ultrashort peptide bioconjugates are exclusively antifungal agents and synergize with cyclodextrin and amphotericin B. Antimcrob. Agents Chemother. 56, 1-9. doi: 10.1128/aac.00468-11

Avrahami, D., and Shai, Y. (2002). Conjugation of a magainin analogue with lipophilic acids controls hydrophobicity, solution assembly, and cell selectivity. Biochemistry 41, 2254-2263. doi: 10.1021/bi011549t

Cassone, M., and Otvos, L. J. (2010). Synergy among antibacterial peptides and between peptides and small-molecule antibiotics. Expert Rev. Anti Infect. Ther. 8, 703-716. doi: 10.1586/eri.10.38

Chih, Y. H., Lin, Y. S., Yip, B. S., Wei, H. J., Chu, H. L., Yu, H. Y., et al. (2015). Ultrashort antimicrobial peptides with antiendotoxin properties. Antimcrob. Agents Chemother. 59, 5052-5056. doi: 10.1128/aac.00519-15

Chih, Y. H., Wang, S. Y., Yip, B. S., Cheng, K. T., Hsu, S. Y., Wu, C. L., et al. (2019). Dependence on size and shape of non-nature amino acids in the enhancement of lipopolysaccharide (LPS) neutralizing activities of antimicrobial peptides. J. Colliod Interface Sci. 533, 492-502. doi: 10.1016/j.jcis.2018. 08.042 the plain peptides and generated a better synergistic effect when combined with conventional antibiotics. Increasing the membrane permeabilization against the bacterial strains was also observed. Additionally, these Nal-tagged AMPs reduced the antibiotic-induced release of LPS from Gram-negative bacteria by more than $99.95 \%$. Only one or two Nal end-tags were needed to have these biological impacts on the peptides, making this a potential strategy for developing new antimicrobial agents.

\section{DATA AVAILABILITY STATEMENT}

The original contributions presented in the study are included in the article/supplementary material, further inquiries can be directed to the corresponding author.

\section{AUTHOR CONTRIBUTIONS}

C-LW, Y-HC, and K-LP performed the experiments and analyzed the data. C-LW and J-WC wrote the manuscript. B-SY and J-WC planned the study and revised the manuscript. All authors contributed to the article and approved the submitted version.

\section{FUNDING}

This work was supported by grants from the Ministry of Science and Technology of Taiwan to J-WC (109-2113-M-007-009) and National Taiwan University Hospital Hsinchu Branch to B-SY.

\section{ACKNOWLEDGMENTS}

We thank Daniel Cheng for editing the manuscript.

Chu, H. L., Chih, Y. H., Peng, K. L., Wu, C. L., Yu, H. Y., Cheng, D., et al. (2020). Antimicrobial peptides with enhanced salt resistance and antiendotoxin properties. Int. J. Mol. Sci. 21:6810. doi: 10.3390/ijms21186810

Chu, H. L., Yu, H. Y., Yip, B. S., Chih, Y. H., Liang, C. W., Cheng, H. T., et al. (2013). Boosting salt resistance of short antimicrobial peptides. Antimcrob. Agents Chemother. 57, 4050-4052. doi: 10.1128/aac.00252-13

Clinical and Laboratory Standards Institute (CLSI) (2015). Performance Standards for Antimicrobial Susceptibility Testing; Twenty-Fifth Informational Supplement. Wayne, PA: Clinical and Laboratory Standards Institute.

Essodaigui, M., Broxterman, H. J., and Garnier-Suillerot, A. (1998). Kinetic analysis of calcein and calcein-acetoxymethylester efflux mediated by the multidrug resistance protein and P-glycoprotein. Biochemistry 37, 2243-2250. doi: 10. 1021/bi9718043

Feng, Q., Huang, Y., Chen, M., Li, G., and Chen, Y. (2015). Functional synergy of a-helical antimicrobial peptides and traditional antibiotics against Gramnegative and Gram-positive bacteria in vitro and in vivo. Eur. J. Clin. Microbiol. Infect. Dis 34, 197-204. doi: 10.1007/s10096-014-2219-3

Godballe, T., Mojsoska, B., Nielsen, H. M., and Jenssen, H. (2016). Antimicrobial activity of GN peptides and their mode of action. Biopolymers 106, 172-183. doi: 10.1002/bip.22796

Joshi, S., Bisht, G. S., Rawat, D. S., Kumar, A., Kumar, R., Maiti, S., et al. (2010). Interaction studies of novel cell selective antimicrobial peptides with model membranes and E coli ATCC 11775. Biochim. Biophys. Acta 1798, 1864-1875. doi: 10.1016/j.bbamem.2010.06.016 
Koo, S. P., Bayer, A. S., and Yeaman, M. R. (2001). Diversity in antistaphylococcal mechanisms among membrane-targeting antimicrobial peptides. Infect. Immun. 69, 4916-4922. doi: 10.1128/iai.69.8.4916-4922.2001

Lazar, V., Martins, A., Spohn, R., Daruka, L., Grezal, G., Fekete, G., et al. (2018). Antibiotic-resistant bacteria show widespread collateral sensitivity to antimicrobial peptides. Nat. Microbiol. 3, 718-731. doi: 10.1038/s41564-0180164-0

Li, D., Yang, Y., Tian, Z., Lv, J., Sun, F., Wang, Q., et al. (2017). Synergistic antibiotic effect of looped antimicrobial peptide CLP-19 with bactericidal and bacteriostatic agents. Oncotarget 8, 55958-55966. doi: 10.18632/oncotarget. 18124

Li, J., Fernandez-Millan, P., and Boix, E. (2020). Synergism between host defence peptides and antibiotics against bacterial infections. Curr. Top. Med. Chem. 20, 1238-1263. doi: 10.2174/1568026620666200303122626

Makovitzki, A., Avrahami, D., and Shai, Y. (2006). Ultrashort antibacterial and antifungal lipopeptides. Proc. Natl. Acad. Sci. U.S.A. 103, 15997-16002. doi: $10.1073 /$ pnas.0606129103

Marston, H. D., Dixon, D. M., Knisely, J. M., Palmore, T. N., and Fauci, A. S. (2016). Antimicrobial resistance. JAMA 316, 1193-1204.

Martinez, M., Goncalves, S., Felicio, M. R., Maturana, P., Santos, N. C., Semorile, L., et al. (2019). Synergistic and antibiofilm activity of the antimicrobial peptide P5 against carbapenem-resistant Pseudomonas aeruginosa. Biochim. Biophys. Acta Biomembr. 1861, 1329-1337. doi: 10.1016/j.bbamem.2019.05.008

Mataraci, E., and Dosler, S. (2012). In vitro activities of antibiotics and antimicrobial cationic peptides alone and in combination against methicillinresistant Staphylococcus aureus biofilms. Antimcrob. Agents Chemother. 56, 6366-6371. doi: 10.1128/aac.01180-12

Mohamed, M. F., Abdelkhalek, A., and Seleem, M. N. (2016). Evaluation of short synthetic antimicrobial peptides for treatment of drug-resistant and intracellular Staphylococcus aureus. Sci. Rep. 6:29707.

Mojsoska, B., and Jenssen, H. (2015). Peptides and peptidomimetics for antimicrobial drug design. Pharmaceuticals (Basel) 8, 366-415. doi: 10.3390/ ph8030366

Morones-Ramirez, J. R., Winkler, J. A., Spina, C. S., and Collins, J. J. (2013). Silver enhances antibiotics activity against gram-negative bacteria. Sci. Transl. Med. 5:190ra81.

Odds, F. C. (2003). Synergy, antagonism, and what the chequerboard puts between them. J. Antimicrob. Chemother. 52:1.

Pasupuleti, M., Chalupka, A., Morgelin, M., Schmidtchen, A., and Malmsten, M. (2009). Tryptophan end-tagging of antimicrobial peptides for increased potency against Pseudomonas aeruginosa. Biochim. Biophys. Acta 1790, 800808. doi: 10.1016/j.bbagen.2009.03.029

Rosenfeld, Y., Lev, N., and Shai, Y. (2010). Effect of the hydrophobicity to net positive charge ratio on antibacterial and anti-endotoxin activities of structurally similar antimicrobial peptides. Biochemistry 49, 853-861. doi: 10 . 1021/bi900724x

Schmidtchen, A., Pasupuleti, M., Morgelin, M., Davoudi, M., Alenfall, J., Chalupka, A., et al. (2009). Boosting antimicrobial peptides by hydrophobic oligopeptide end tags. J. Biol. Chem. 284, 17584-17594. doi: 10.1074/jbc.m109.011650

Schmidtchen, A., Ringstad, L., Kasetty, G., Mizuno, H., Rutland, M. W., and Malmsten, M. (2011). Membrane selectivity by W-tagging of antimicrobial peptides. Biochim. Biophys. Acta 1808, 1081-1091. doi: 10.1016/j.bbamem. 2010.12.020

Serrano, G. N., Zhanel, G. G., and Schweizer, F. (2009). Antibacterial activity of ultrashort cationic lipo-b-Peptides. Antimcrob. Agents Chemother. 53, 22152217. doi: 10.1128/aac.01100-08

Sierra, J. M., Fuste, E., Rabanal, F., Vinuesa, T., and Vinas, M. (2017). An overview of antimicrobial peptides and the latest advances in their development. Expert Opin. Biol. Ther. 17, 663-676. doi: 10.1080/14712598.2017.1315402

Song, J., Wang, J., Zhan, N., Sun, T., Yu, W., Zhang, L., et al. (2019). Therapeutic potential of Trp-Rich engineered amphiphiles by single hydrophobic amino acid end-tagging. ACS Appl. Mater. Interfaces 11, 43820-43834. doi: 10.1021/ acsami.9b12706

Stokes, J. M., French, S., Ovchinnikova, O. G., Bouwman, C., Whitfield, C., and Brown, E. D. (2016). Cold stress makes Escherichia coli susceptible to glycopeptide antibiotics by altering outer membrane integrity. Cell Chem. Biol. 23, 267-277. doi: 10.1016/j.chembiol.2015.12.011

Trautmann, M., Heinemann, M., Zick, R., Moricke, A., Seidelmann, M., and Berger, D. (1998). Antibacterial activity of meropenem against Pseudomonas aeruginosa, including antibiotic-induced morphological changes and endotoxin-liberating effects. Eur. J. Clin. Microbiol. Infect. Dis 17, 754-760. doi: 10.1007/s100960050180

Vaara, M. (2019). Polymyxin derivatives that sensitize gram-negative bacteria to other antibiotics. Molecules 24:249. doi: 10.3390/molecules24020249

Wu, C. L., Hsueh, J. Y., Yip, B. S., Chih, Y. H., Peng, K. L., and Cheng, J. W. (2020). Antimicrobial peptides display strong synergy with vancomycin against vancomycin-reisstant E. faecium, S. aureus, and wild-type E. coli. Int. J. Mol. Sci. 21:4578. doi: 10.3390/ijms21134578

Wu, X., Li, Z., Li, X., Tian, Y., Fan, Y., Yu, C., et al. (2017). Synergistic effects of antimicrobial peptide DP7 combined with antibiotics against multidrugresistant bacteria. Drug Des. Devel. Ther. 11, 939-946. doi: 10.2147/dddt. s107195

Xiong, Y. Q., Mukhopadhyay, K., Yeaman, M. R., Adler-Moore, J., and Bayer, A. S. (2005). Functional interrelationships between cell membrane and cell wall in antimicrobial peptide-mediated killing of Staphylococcus aureus. Antimicrob. Agents Chemother. 49, 3114-3121. doi: 10.1128/aac.49.8.3114-3121. 2005

Yu, H. Y., Chen, Y. A., Yip, B. S., Wang, S. Y., Wei, H. J., Chih, Y. H., et al. (2017). Role of b-naphthylalanine end-tags in the enhancement of antiendotoxin activities: solution structure of the antimicrobial peptide S1-Nal-Nal in complex with lipopolysaccharide. Biochim. Biophys. Acta 1859, 1114-1123. doi: 10.1016/ j.bbamem.2017.03.007

Yu, H. Y., Huang, K. C., Yip, B. S., Tu, C. H., Chen, H. L., Cheng, H. T., et al. (2010). Rational design of tryptophan-rich antimicrobial peptides with enhanced antimicrobial activities and specificities. Chembiochem 11, 22732282. doi: $10.1002 /$ cbic. 201000372

Yu, H. Y., Yip, B. S., Tu, C. H., Chen, H. L., Chu, H. L., Chih, Y. H., et al. (2013). Correlations between membrane immersion depth, orientation, and salt-resistance of tryptophan-rich antimicrobial peptides. Biochim. Biophys. Acta 1828, 2720-2728.

Zharkova, M. S., Orlov, D. S., Golubeva, O. Y., Chakchir, O. B., Eliseev, I. E., Grinchuk, T. M., et al. (2019). Application of antimicrobial peptides of the innate immune system in combination with conventional antibiotics-a novel way to combat antibiotic resistance. Front. Cell. Infect. Microbiol. 9:128. doi: $10.3389 /$ fcimb.2019.00128

Conflict of Interest: The authors declare that the research was conducted in the absence of any commercial or financial relationships that could be construed as a potential conflict of interest.

Publisher's Note: All claims expressed in this article are solely those of the authors and do not necessarily represent those of their affiliated organizations, or those of the publisher, the editors and the reviewers. Any product that may be evaluated in this article, or claim that may be made by its manufacturer, is not guaranteed or endorsed by the publisher.

Copyright $\odot 2021$ Wu, Peng, Yip, Chih and Cheng. This is an open-access article distributed under the terms of the Creative Commons Attribution License (CC BY). The use, distribution or reproduction in other forums is permitted, provided the original author(s) and the copyright owner(s) are credited and that the original publication in this journal is cited, in accordance with accepted academic practice. No use, distribution or reproduction is permitted which does not comply with these terms. 